OPEN ACCESS

Edited by: Martin Kukwa,

University of Gdansk, Poland

Reviewed by:

Nicolas Magain,

University of Liège, Belgium Kristiina Mark,

Estonian University of Life Sciences,

Estonia

${ }^{*}$ Correspondence:

Miguel Blázquez

m.blazquezva@rib.csic.es

Specialty section:

This article was submitted to Microbe and Virus Interactions With

Plants,

a section of the journal

Frontiers in Microbiology

Received: 27 September 2021

Accepted: 02 December 2021

Published: 03 January 2022

Citation:

Blázquez M, Hernández-Moreno LS,

Gasulla F, Pérez-Vargas I and Pérez-Ortega S (2022) The Role of

Photobionts as Drivers of

Diversification in an Island Radiation

of Lichen-Forming Fungi.

Front. Microbiol. 12:784182.

doi: 10.3389/fmicb.2021.784182

\section{The Role of Photobionts as Drivers of Diversification in an Island Radiation of Lichen-Forming Fungi}

\author{
Miguel Blázquez 1,2,3*, Lucía S. Hernández-Moreno ${ }^{1,2}$, Francisco Gasulla ${ }^{4}$, \\ Israel Pérez-Vargas ${ }^{5}$ and Sergio Pérez-Ortega ${ }^{1,2}$ \\ 'Department of Mycology, Real Jardín Botánico (CS/C), Madrid, Spain, ㄹpen Access Publication Support Program, \\ Consejo Superior de Investigaciones Científicas (CSIC), Madrid, Spain, ${ }^{3}$ Escuela Internacional de Doctorado, Universidad \\ Rey Juan Carlos, Móstoles, Spain, ${ }^{4}$ Department of Life Sciences, Universidad de Alcalá, Alcalá de Henares, Spain, \\ ${ }^{5}$ Department of Botany, Ecology and Plant Physiology, Universidad de La Laguna, San Cristóbal de La Laguna, Spain
}

Speciation in oceanic islands has attracted the interest of scientists since the 19th century. One of the most striking evolutionary phenomena that can be studied in islands is adaptive radiation, that is, when a lineage gives rise to different species by means of ecological speciation. Some of the best-known examples of adaptive radiation are charismatic organisms like the Darwin finches of the Galapagos and the cichlid fishes of the great African lakes. In these and many other examples, a segregation of the trophic niche has been shown to be an important diversification driver. Radiations are known in other groups of organisms, such as lichen-forming fungi. However, very few studies have investigated their adaptive nature, and none have focused on the trophic niche. In this study, we explore the role of the trophic niche in a putative radiation of endemic species from the Macaronesian Region, the Ramalina decipiens group. The photobiont diversity was studied by Illumina MiSeq sequencing of the ITS2 region of 197 specimens spanning the phylogenetic breadth and geographic range of the group. A total of 66 amplicon sequence variants belonging to the four main clades of the algal genus Trebouxia were found. Approximately half of the examined thalli showed algal coexistence, but in most of them, a single main photobiont amounted to more than $90 \%$ of the reads. However, there were no significant differences in photobiont identity and in the abundance of ITS2 reads across the species of the group. We conclude that a segregation of the trophic niche has not occurred in the $R$. decipiens radiation.

Keywords: Macaronesia, Ramalina, trophic niche, metabarcoding, adaptive radiation

\section{INTRODUCTION}

Oceanic islands, which are of volcanic origin and have never been connected to continental land masses, have attracted the interest of scientists since the 19th century, using them as natural laboratories in which to study the origin of biodiversity and its evolution (Whittaker and Fernández-Palacios, 2007; Warren et al., 2015). Perhaps the best-studied evolutionary phenomenon on oceanic islands has been that of cladogenetic speciation, that is, how from a colonization event a lineage radiates into a collection of species (Gould and Eldredge, 1977). 
Radiations can be adaptive or non-adaptive (Gittenberger, 1991; Schluter, 2000; Rundell and Price, 2009). Non-adaptive radiations are those in which diversification is not accompanied by niche differentiation and usually gives rise to ecologically similar allopatric species (Gittenberger, 1991; Rundell and Price, 2009). On the other hand, in adaptive radiations, ecological speciation is the driver of diversification, and niche differentiation among radiation-originating species allows sympatric patterns (Schluter, 2000). One key point in defining an adaptive radiation is that the traits presented by the species (phenotype) must have a clear correlation with the environment in which the species occur (Schluter, 2000; Givnish, 2015). Therefore, in the study of the adaptive nature of a radiation, it is essential to study the variability of functional traits in the species of the radiation and their correlation with abiotic factors. The best-studied examples of adaptive radiation have focused on charismatic organisms, such as the Darwin finches of the Galápagos Islands (Grant and Grant, 2008), the silversword alliance of Hawaii (Landis et al., 2018), or the Anolis lizards of the Greater Antilles (Losos, 2009). However, the number of studies that have investigated the adaptive nature on radiations of other groups of less charismatic organisms is still very limited (Gaya et al., 2015; Mao et al., 2018).

Lichens are the symbiotic phenotype of fungi with a specialized type of nutrition that takes sugars from a population of extracellular algae and/or cyanobacteria (hereafter, the photobionts). Thus, for lichen-forming fungi (hereafter, the mycobionts), the identity and abundance of their associated photobionts constitute the trophic dimension of their ecological niche. Although more than 50 genera of algae and cyanobacteria are known to act as lichen photobionts (Friedl and Büdel, 2008; Sanders and Masumoto, 2021), the vast majority of the nearly 20,000 described species of lichen-forming fungi (Lücking et al., 2017) are associated with algae from the class Trebouxiophyceae (Friedl and Büdel, 2008). Among the Trebouxiophyceae, the species of the genus Trebouxia are the most common photobionts (Friedl and Büdel, 2008; Muggia et al., 2020). The role of photobionts as drivers of speciation in lichen-forming fungi is still poorly known. There are several factors that may determine the contribution of photobionts in mycobiont diversification (Singh et al., 2017). On the one hand, it has been proposed that photobiont niches are influenced by abiotic conditions and these preferences may limit lichen distributions (Peksa and Škaloud, 2011). It has been shown that photobiont switches between physiologically compatible photobionts are mechanisms to widen the mycobiont ecological niches and geographic ranges (Fernández-Mendoza et al., 2011; del Campo et al., 2013; Rolshausen et al., 2018, 2020) or for ecological speciation (Ortiz-Álvarez et al., 2015). On the other hand, not all mycobiont species show similar specialization toward their photobionts (Pérez-Ortega et al., 2012; Magain et al., 2017), ranging from narrow specialists (Garrido-Benavent et al., 2017) to generalists (Muggia et al., 2014). In addition, different Trebouxia species have been found to coexist inside a single lichen thallus (Piercey-Normore, 2006; del Campo et al., 2010; Muggia et al., 2013). These species show differences in various aspects of their physiology, such as growth rate
(Casano et al., 2011), photosynthetic output (Casano et al., 2011), response to oxidative stress (del Hoyo et al., 2011), and heavy metal tolerance (Álvarez et al., 2015). It is still not clear whether coexistence is a widespread phenomenon or it is reduced to certain species or lineages, and its significance in ecological and evolutionary times.

Ramalina is a well-known genus of lichen-forming fungi which forms usually large fruticose thalli of a more or less light-yellow color. The genus belongs to a clade of fruticose genera in the Ramalinaceae (Spjut et al., 2020), a family dominated by microlichens (Kistenich et al., 2018). The genus is subcosmopolitan and with c. 230 species is one of the largest genera of lichen-forming fungi (Lücking et al., 2017). Most of its diversity is concentrated in five areas: The Andes (Marcano et al., 2021), East Africa (Krog and Swinscow, 1976), Baja California (Bowler and Rundel, 1972, 1973), Australasia (Stevens, 1987; Blanchon et al., 1996) and Macaronesia (Krog and Østhagen, 1980a,b; Krog, 1990). Macaronesia is a group of volcanic archipelagos in the North Atlantic: Azores, Cape Verde, Canary Islands, Madeira, and Selvagens Islands. In spite of the small area, a total of 37 species of Ramalina have been recorded from the area, of which 25 are endemic (68\%, most outstanding being the island of Porto Santo which, with an area of $42 \mathrm{~km}^{2}$, hosts a total of 6 endemic Ramalina species (Sparrius et al., 2017). Among the endemic species of Ramalina in Macaronesia two groups of saxicolous species stand out, the $R$. bourgaeana group and the $R$. decipiens group, which are defined by the presence of characteristic structures, chondroid strands embedded in the medulla in the former and adjacent to the cortex in the later (Krog and Østhagen, 1980a; Spjut et al., 2020). The taxonomy of the Ramalina decipiens group has been recently revisited through an integrative approach recognizing 15 species-level lineages, six of which are newly described and two remain formally undescribed (Blázquez et al., in prep.). Of the fifteen recognized species, all are endemic to Macaronesia, except $R$. maderensis, which has also been reported from Saint Helena (Aptroot, 2008). In addition, most of them are single-island endemics, but two species ( $R$. decipiens and $R$. maderensis) are widespread.

In this study, we hypothesize that photobiont-mycobiont associations play an important role in adaptive radiations of lichen-forming fungi. Photobiont differences among the species of a radiating clade of mycobionts, either in identity or abundance, could indicate a segregation of the trophic niche of the clade. We propose the Ramalina decipiens group as a framework to study the role of trophic niche segregation as a key driver in adaptive radiation. In order to explore and test this hypothesis, we are to analyze (i) the diversity of the photobionts associated with the species of the $R$. decipiens group, (ii) the relative importance of mycobiont identity, island, and macroclimate on photobiont community structure, (iii) the level of specialization of each Ramalina species toward its photobionts and (iv) whether specialization and photobiont diversity are phylogenetically structured. In addition, as algal coexistence has been previously reported in Ramalina species, we also intend (v) to explore to what extent this phenomenon occurs in the group. 


\section{MATERIALS AND METHODS}

\section{Sampling}

We studied 197 specimens of the $R$. decipiens group representing the 15 species-level lineages (Blázquez et al. in preparation). Seven of those species correspond to previously known species (Krog and Østhagen, 1980a,b; Krog, 1990). Another six represent new species which are going to be described in Blázquez et al. (in preparation). They are referred here with the following provisional names: $R$. delicata nom. Prov., $R$. fortunata nom. Prov., R. gomerana nom. Prov., $R$. papyracea nom. Prov., $R$. sabinosae nom. Prov., and $R$. sampaiana nom. Prov. Two further species-level lineages will remain unnamed until further material is available and are referred in the present study as Ramalina sp. 1 and Ramalina sp. 2. The specimens were collected throughout 66 localities spanning the seven Canary Islands, the islands of Madeira and Porto Santo of the Madeira archipelago, and the islands of Sal and São Vicente of the Cape Verde archipelago (Supplementary Table 1).

\section{DNA Extraction, Amplification, and Sequencing}

A small thallus fragment from each specimen (c. $10 \mathrm{~mm}^{2}$ ) was excised from the tip of a single laciniae with the help of razor blade and forceps under a Nikon SMZ800 stereomicroscope. First, we inspected the thalli under a x80 magnification to check for areas free of epiphytic microalgae and fungi. Thallus tips were the only zones free of epiphytes in all samples. The choice of thallus tips is also supported by the finding of Molins et al. (2021), who reported that there were no differences in photobiont composition among different parts of the thallus in specimens of a species of the same genus ( $R$. farinacea) from the same biogeographic region as the present study. Samples were washed with acetone to remove secondary metabolites and stored at $-80^{\circ} \mathrm{C}$. After $1 \mathrm{~h}$ of freezing, they were pulverized using TissueLyser II (Qiagen) with two crystal beads. Genomic DNA was extracted using E.Z.N.A. ${ }^{\circledR}$ Forensic DNA Kit (Omega Bio-Tek), following the instructions of the manufacturer. The second region of the ribosomal internal transcriber spacer (ITS2) was used as barcode to prospect photobiont diversity. We used primers FDGITS2-f and FDGITS2-r (Dal Grande et al., 2018) for amplification. These primers included Fluidigm CS1 and CS2 universal oligomer sequences at their $5^{\prime}$ ends. PCR reactions were carried out in a total volume of $15 \mu \mathrm{l}$, containing $3 \mu \mathrm{l}$ of template DNA, $0.3 \mu \mathrm{l}$ of each primer $(10 \mu \mathrm{M}), 0.6 \mu \mathrm{l}$ of MyFi DNA Polymerase (Bioline, Sydney, Australia), $3 \mu \mathrm{l}$ of 5x MyFi Reaction Buffer, and $7.8 \mu \mathrm{l}$ of distilled water. PCR settings consisted in an initial denaturation at $95^{\circ} \mathrm{C}$ for $1 \mathrm{~min} ; 35$ cycles of $95^{\circ} \mathrm{C}$ for $15 \mathrm{~s}, 54^{\circ} \mathrm{C}$ for $15 \mathrm{~s}$, and $72^{\circ} \mathrm{C}$ for $15 \mathrm{~s}$; with a final extension at $72^{\circ} \mathrm{C}$ for $5 \mathrm{~min}$. PCR products were checked in $1 \%$ agarose gels stained with SYBR $^{\text {TM }}$ Safe DNA Gel Stain (Thermo Fisher Scientific). PCR products were quantified using the Qubit dsDNA HS (High Sensitivity) Assay Kit (Thermo Fisher Scientific) and pooled in equimolar concentrations for sequencing on a single MiSeq run (Illumina, United States) at the RTSF Genomics Core at
Michigan State University (East Lansing, Michigan). The Genomics Core completed library preparation by secondary PCR targeting the Fluidigm CS1/CS2 oligos at the ends of the primary PCR products. Primers used for the second PCR included dual indexed, Illumina library compatible sequences. Finished libraries were bulk normalized using Invitrogen SequalPrep DNA Normalization Plates (Thermo Fisher Scientific) and the recovered products pooled. The pool was QC'd and quantified using a combination of Qubit dsDNA HS (Thermo Fisher Scientific), Agilent 4,200 TapeStation HS DNA1000 (Agilent Technologies), and Kapa Illumina Library Quantification qPCR assays (Kapa Biosystems, Inc.). This pool was loaded onto an Illumina MiSeq v2 Standard flow cell and sequencing performed in a 2x250bp paired-end format using a MiSeq v2 500 cycle reagent cartridge. Custom sequencing and index primers complementary to the Fluidigm CS1/CS2 oligos were added to appropriate wells of the reagent cartridge. Base calling was done by Illumina Real-Time Analysis (RTA) v1.18.54, and output of RTA was demultiplexed and converted to FastQ format with Illumina Bcl2fastq v2.19.1.

\section{Sequence Processing}

Raw sequence data were processed using the DADA2 pipeline (Callahan et al., 2016) in R 4.0.3 (R Core Team, 2020). DADA2 takes a set of demultiplexed paired-end fastq files, filters the sequences based on their length and quality, assembles them into error-corrected amplicon sequence variants (ASVs), and removes chimeric ASVs. We chose this pipeline because ASVs make possible to work at a finer resolution than other approaches based on the creation of operational taxonomic units (OTUs). Besides, ASVs allow for greater reproducibility, reusability, and comprehensiveness than OTUs (Callahan et al., 2017). Following Dal Grande et al. (2018) we considered that ASVs that represented $<0.005 \%$ (i.e., $\mathrm{n}=100$ ) of the total reads were most probably exogenous to the symbiosis and did not include them in downstream analyses. We then assigned taxonomy to the ASVs using all sequences assembled by Muggia et al. (2020) as a taxonomic reference. This was done using the assignTaxonomy function in DADA2. Given that microalgae can show ecophysiological differences even when they are phylogenetically close (Sadowsky et al., 2016) we chose to conduct all analyses in this study at the ASV level. All sequences obtained in this study are available in the SRA (NCBI) under BioProject PRJNA764073.

\section{Alignment, Phylogenetic Relationships, and ASV Haplotype Networks}

ASVs were aligned using MAFFT v.7.308 (Katoh et al., 2002) as implemented in Geneious ${ }^{\circledR}$ v.9.1.8. Sequences of Asterochloris glomerata (MW043487, Pino-Bodas and Stenroos, 2021) and Vulcanochloris guanchorum (KR952330, Vančurová et al., 2015) were included as outgroup. We inferred phylogenetic relationships among ASVs using Maximum Likelihood using RAxMLHPC2 v. 8.2.4 (Stamatakis, 2014) as implemented in CIPRES Science Gateway (Miller et al., 2011). We selected the GTRGAMMA substitution model and carried out 1,000 rapid bootstrap 
pseudoreplicates to evaluate nodal support. We considered nodes with bootstrap values equal or higher than $70 \%$ to be significantly supported. The resulting phylogenetic tree was visualized in FigTree 1.4.4 ${ }^{1}$ and edited using Adobe Illustrator CS5 (Adobe Systems Inc., San José, United States). Additionally, we generated haplotype networks for the Trebouxia species represented by more than three ASVs. We used the TCS method (Templeton et al., 1992) as implemented in PopART v.1.7 (Leigh and Bryant, 2015) for network construction. These networks were edited in Adobe Illustrator CS5 to show the prevalence of the different recovered ASV in each sampled Ramalina species and island.

\section{Differences in Frequency of ASVs in Islands and Species}

To explore whether the frequency of ASVs was different among islands and Ramalina species we adjusted a two-way ANOVA for each ASV. ASV frequency was used as the response variable and island and Ramalina species as explanatory variables. We used Levene's test to check whether data for each ASV met the normality assumption necessary to carry out a two-way ANOVA. In the cases in which our data did not meet the assumptions, we employed the non-parametric Kruskal-Wallis test. This was done using the functions aov, leveneTest, and kruskal.test in base R 4.0.3 (R Core Team, 2020). ASVs occurring only in one specimen were not included in this analysis.

\section{Photobiont Community Structure}

In order to explore the relative importance of mycobiont identity, macroclimate, and island in shaping photobiont communities we performed distance-based redundancy analysis (dbRDA, Legendre and Anderson, 1999). Following Shankar et al. (2017), we calculated an abundance-weighed phylogenetic UniFrac distance-based dissimilarity matrix. This was done with the $\mathrm{R}$ package phyloseq (McMurdie and Holmes, 2013). We transformed the ASV table into relative ASV abundances using the function decostand of the vegan package (Oksanen et al., 2012) with the method "total" and combined it with the taxonomy of the ASVs and the RAxML phylogeny previously generated into a phyloseq object using the merge_phyloseq function. The dissimilarity matrix was calculated from this object using the UniFrac function. The weighed UniFrac dissimilarity matrix was used as the response matrix in the dbRDA. We used three explanatory matrices: (1) first matrix corresponded to the Ramalina species, (2) second to the island where samples were collected, (3) and third matrix included five macroclimatic variables downloaded from WorldClim (Fick and Hijmans, 2017): average temperature $\left({ }^{\circ} \mathrm{C}\right)$, precipitation $(\mathrm{mm})$, solar radiation $\left(\mathrm{kJ} \mathrm{m}^{-2} \mathrm{day}^{-1}\right)$, wind speed $\left(\mathrm{m} \mathrm{s}^{-1}\right)$, and water vapor pressure $(\mathrm{kPa})$. Because lichens are photosynthetic and poikilohydric symbioses, we chose to use these instead of the 19 widely used bioclimatic variables also available in WorldClim, that are derived from temperature and rainfall only. All layers of the five variables (data for each month of the year are

${ }^{1}$ http://tree.bio.ed.ac.uk/software/figtree/ available) were downloaded at a resolution of $30 \mathrm{~s}\left(\sim 1 \mathrm{~km}^{2}\right)$ and merged into year averages using the calc function of the raster $\mathrm{R}$ package (Hijmans et al., 2015). Then, variable values for each sample were obtained through their geographic coordinates using the extract function from the raster package. Before computing the dbRDA we checked for correlation between WorldClim variables in our samples. We calculated a Pearson correlation coefficient matrix and generated a correlation hierarchical cluster plot with the absolute correlation values. Precipitation and water vapor pressure were dropped as they were correlated (absolute correlation $>0.5$ ) with solar radiation and average temperature, respectively. Then we inspected the remaining variables to check their normality. To do so we generated a histogram for each variable with the hist function of base R. Solar radiation was found to be not normal and was log-transformed. dbRDA was then calculated with the dbrda function of the vegan $\mathrm{R}$ package (Oksanen et al., 2012). Variance partitioning between the three explanatory matrices was estimated using adjusted $\mathrm{R}^{2}$. Adjusted $\mathrm{R}^{2}$ significance was assessed for each fraction with a permutation-based ANOVA test with 2000 permutations. This was done in vegan using the functions varpart and anova.cca. Significance of the dbRDA as a whole was also assessed with a permutation-based ANOVA test with 2000 permutations, this time with the function anova. To visualize variance partitioning we generated a Venn diagram plotting the output of the varpart function.

\section{Algal Co-occurrence Analyses}

Based on the ASVs abundance table we calculated for each Ramalina species: number of studied thalli, percentage of thalli that showed algal coexistence, minimum number of ASVs in one thallus, mean number of ASVs per thallus, and maximum number of ASVs in one thallus. For the species that showed algal coexistence, we also calculated: minimum relative abundance of the main photobiont found in one thallus, mean relative abundance of the main photobiont across all thalli showing algal coexistence and maximum relative abundance of the main photobiont found in one thallus.

\section{Bipartite Network, Specialization, and Modularity}

We built two different adjacent matrices $i \times j$, where $i$ represents mycobionts and $j$ ASVs. In the first matrix, interaction frequency between mycobiont $i$ and ASV $j$ was calculated as the sum of reads for ASV $j$ found in all specimens of mycobiont $i$ previously rarefied to the depth of the sample with the lower number of reads (Weiss et al., 2017). In the second matrix, number of read are not taken into account and the interaction frequency was based in the number of specimens of the mycobiont $i$ where ASV $j$ was found. The rarefaction was done with the rarefy_even_depth function of the phyloseq (McMurdie and Holmes, 2013) R package. The presence-absence conversion was done using the function decostand of the vegan package (Oksanen et al., 2012) with the method "pa." For each network, we calculated the parameter $d$ ' (Blüthgen et al., 2006) to estimate the specialization of the mycobionts toward 
the ASVs. This index ranges from 0 (no specialization) to 1 (high specialization). We also calculated species degree, which is the sum of links per species, and $N D$, which is species degree normalized by the number of possible partners. All analyses were carried out in the $\mathrm{R}$ package bipartite (Dormann et al., 2008), using the functions plotweb and specieslevel. Following the approach of Gómez et al. (2015), we used the quantitative modularity $(Q)$ of the bipartite networks to explore the occurrence of different photobiont niches in the species of the $R$. decipiens group. Optimal modular configuration was calculated using the Beckett algorithm (Beckett, 2016) as implemented in the computeModules function of the bipartite package. The algorithm was run 20 times with $10^{8}$ MCMC steps and a tolerance level of $10^{-10}$, retaining the iteration with the highest likelihood value as the optimal modular configuration. In order to check for significance, we built a null model based on 500 random networks calculated using the function nullmodel and the vaznull null model which implements the null model proposed by Vázquez et al. (2007) in which matrix connectance remains the same as in the original network but total marginals change. We calculated modularity for each of the random matrices and calculated a $z$-score as $\left(\mathrm{X}_{\text {observed }}-\mu_{\text {null }}\right) / \sigma_{\text {null }}$, being $\mathrm{X}_{\text {observed }}$ the actual value of the parameter, $\mu_{\text {null }}$ the mean of the parameter for the population of matrices in the null model, and $\sigma_{\text {null }}$ their standard deviation. $p$-values for the $z$-score were calculated as the number of elements of the null model showing higher or lower values than the observed value divided by the total number of elements in the null model. To explore if the resulting modules were a consequence of the species geographic distribution we compared the geographic distances within and between modules. This was done with PERMANOVA tests using the adonis function of the vegan $\mathrm{R}$ package (Oksanen et al., 2012). The geographic distance matrix was obtained with the distm function of the geosphere R package (Hijmans et al., 2017).

\section{Genetic Diversity Statistics}

We calculated genetic diversity statistics at both the island and Ramalina species levels. We used the software DnaSP v.6.12.01 to calculate two indices: haplotype diversity ( $H d$, Nei, 1987), and nucleotide diversity ( $\pi$, Nei, 1987). $\pi$ was calculated using the Jukes and Cantor correction (Lynch and Crease, 1990). Instead of using the raw ASVs abundance table as input, we generated DNA alignments for each species and each island, which included a representative sequence of each ASV present in each sample. The two indices were then calculated for each alignment.

\section{Phylogenetic Signal}

We used the phylogeny of the $R$. decipiens group which will be published in a forthcoming paper (Blázquez et al. unpublished) to calculate the phylogenetic signal of the specialization, species degree, ND, haplotype diversity and nucleotide diversity. We employed two different methods to calculate the phylogenetic signal: Pagel's $\lambda$ (Pagel, 1999) as implemented in the phylosig function of the phytools R package (Revell, 2012) and Blomberg's
$K$ (Blomberg et al., 2003) as implemented in the phylosignal function of the picante R package (Kembel et al., 2010). Pagel's $\lambda$ can have values between 0 (no phylogenetic signal) and 1 (Brownian motion model, that is, correlation among trait values is proportional to the extent of shared ancestry). Blomberg's $K$ can be interpreted as follows: if $K=1$ the trait under analysis follows a mode of evolution that is consistent with Brownian motion. If $\mathrm{K}>1$ close relatives are more similar than expected under Brownian motion. On the other hand, in $\mathrm{K}$ values $<1$ close relatives are less similar than expected (Blomberg et al., 2003).

\section{RESULTS}

\section{Phylogenetic Relationships, Haplotype Networks, and Frequency of ASVs}

We obtained a total of 2,949,259 raw reads, of which 2,175,408 passed DADA2 quality filter. After removing ASVs represented by less than 100 reads, 66 ASVs remained (Figure 1). The 66 ASVs clustered into the four main Trebouxia clades (Leavitt et al., 2015; Muggia et al., 2020), but not into the newly reported clade D (Xu et al., 2020). 62 ASVs belonged to four formally described species (i.e., Trebouxia jamesii, T. aggregata, T. decolorans, and T. australis) and to nine of the undescribed Trebouxia lineages reported by Muggia et al. (2020). Four ASVs did not match with any of the sequences assembled by Muggia et al. (2020). These ASVs represented three new lineages, two of them in clade A and one in clade I. Thirty-three of the 66 ASVs clustered into Trebouxia A39. This clade was identified as Trebouxia sp. TR9 through its reference sequence (FJ418565). The most common photobionts found in this study were ASVs 1 and 2, both belonging to Trebouxia sp. TR9 (Figure 2) and diverging by just one nucleotide. They were present on all islands and often coexist in the same localities. These two ASVs were the most common photobionts in the Canarian and Madeira archipelagos, together they represented the main photobionts in 78 and $85 \%$ of the Canarian and Madeiran thalli, respectively. Regarding the Cape Verde archipelago, the main photobionts from all samples corresponded to one of the five ASVs placed in the Trebouxia clade C25. On the other hand, 41 ASVs were only found in one thallus, although only 6 of them acted as the main photobiont.

ASVs belonging to Trebouxia clades A and C were found in all archipelagos. Clades I and $\mathrm{S}$ were not found in Cape Verde samples. Mycobiont identity had a limited effect on the frequency of ASVs (Table 1). Of the 25 ASVs present in more than one thallus only one, belonging to the species Trebouxia jamesii, was significantly associated to some Ramalina species. The island of origin had a greater influence on ASV frequency, with a significant effect in 8 of the 25 included ASVs. The greatest effect was observed in ASVs 5, 7, and 11. These three ASVs belong to Trebouxia clade C 25 and act as main photobionts in thalli collected in Cape Verde, but also occur in small numbers in El Hierro, La Gomera, and Porto Santo. An interaction between island an mycobiont identity was found in ASV 9. However, this ASV only occurs in three thalli: Two specimens of $R$. decipiens collected in Fuerteventura and one of $R$. sp. 2 collected in La Gomera. 


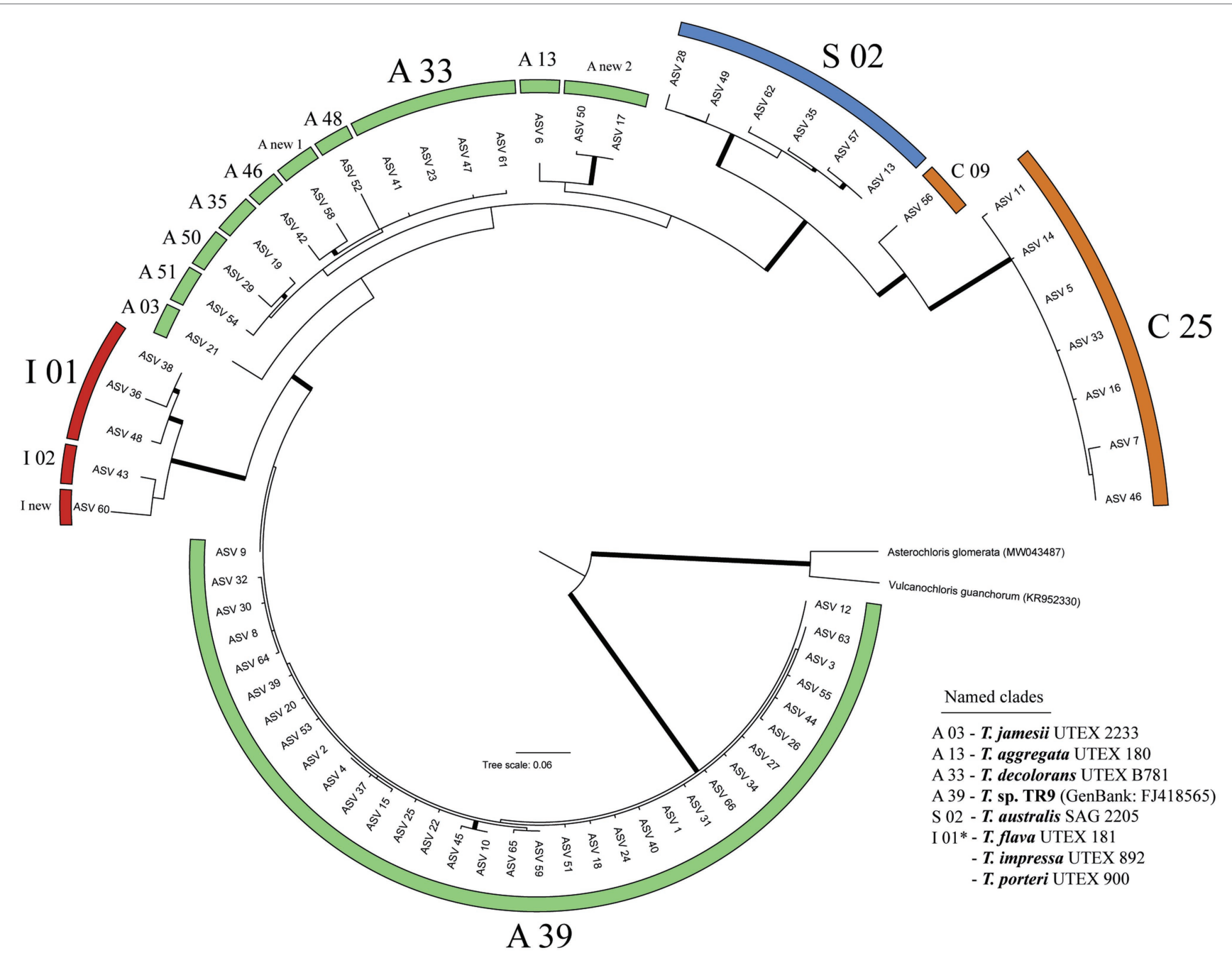

FIGURE 1 | RAxML phylogeny of the 66 ASVs. Branches with bootstrap support higher than 70 are highlighted in bold. Clade nomenclature follows Muggia et al. (2020). Formally described Trebouxia lineages are indicated with UTEX or SAG culture numbers.

\section{Photobiont Community Structure}

The dbRDA analysis returned a $F=3.265$ with a $p=0.001$. The constrained axes explained 0.34 of the variance in ASV community structure (Figure 3). Island was the variable with the greatest simple effect. On the other hand, macroclimate was the variable with the smallest simple effect. However, the main driver of ASV community structure was the mixed effect of island and macroclimate, explaining a greater variance proportion than all other simple and mixed effects combined. Mycobiont identity was the least important variable, taking its simple and mixed effects into account.

\section{Co-occurrence Analyses and Frequency of ASVs}

Out of 197 thalli studied, 102 showed coexistence of several ASVs (51.77\%). Specimens from the Canary Islands and Cape Verde showed a higher proportion of multiple ASVs within the thallus (56 and 58\%, respectively) than specimens from the Madeira archipelago (38\%). Algal coexistence was observed in all species (Table 2) except Ramalina sp. 1, which is most likely an artifact given that the species is represented in our dataset by only one specimen. The mean number of ASVs per thallus was 2.19, with a median of 2. Mean ASV count per thallus ranged from 1.30 in Ramalina hamulosa to 4.67 in Ramalina pluviariae. The sample with the highest ASV count was a Ramalina maderensis collected in Lanzarote (SPO 6337) containing 10 algae. However, on average the main photobiont amounted to $94 \%$ of the reads in thalli showing algal coexistence. The mean abundance of the main photobiont in thalli showing coexistence ranged from $83 \%$ in Ramalina erosa to $99 \%$ in Ramalina sp. 2. There were only six thalli, of varied origin and representing four Ramalina species, in which the main photobiont accounted for less than $70 \%$ of the reads. In most of them, the main and secondary photobionts were different ASVs belonging to the same Trebouxia species. 
A

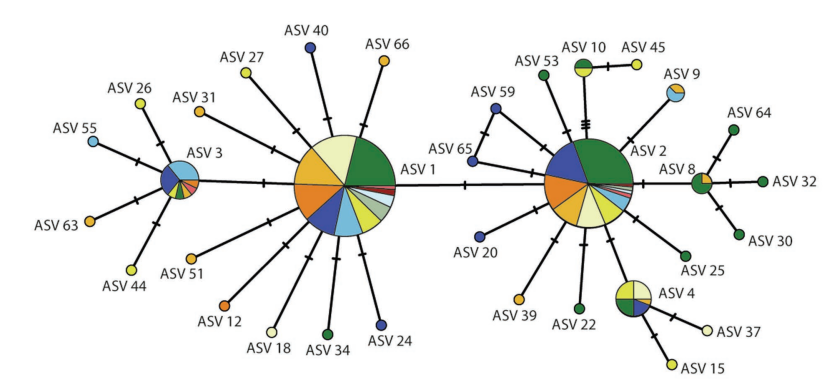

T. A33 (T. decolorans) T. S02 (T. australis)
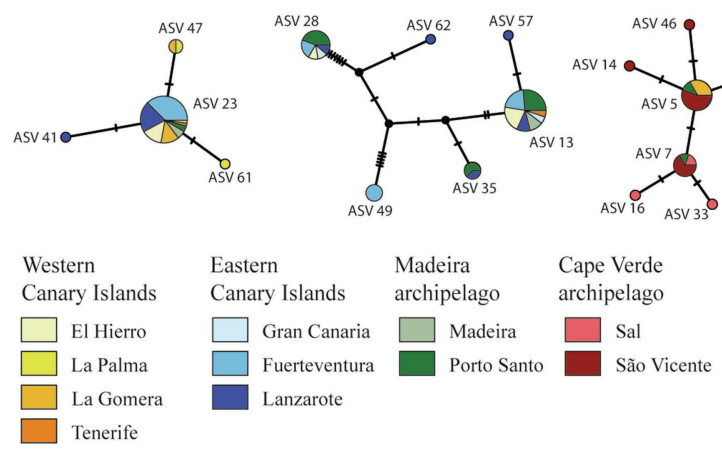

B

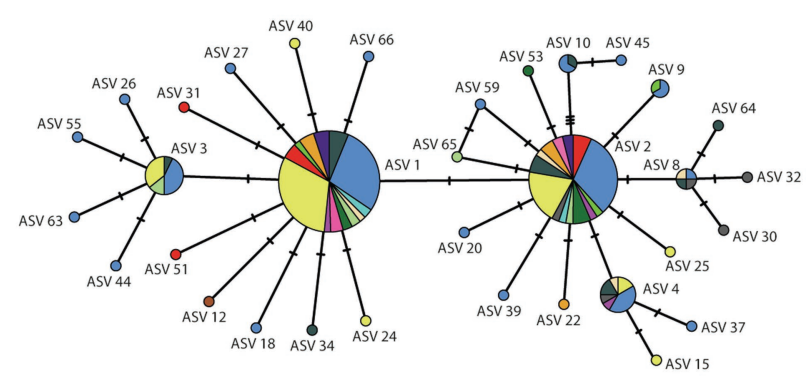

T. A33 (T. decolorans)

T. S02 (T. australis)

T. $\mathrm{C} 25$
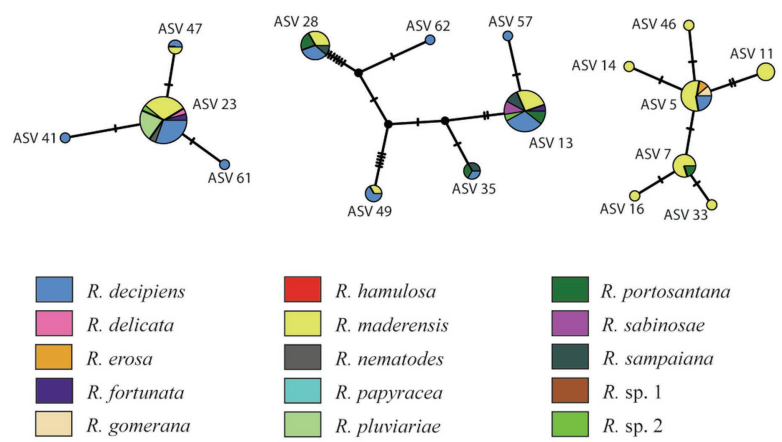

B) mycobiont species. The size of the circles is proportional to the number of samples

FIGURE 2 | TCS networks of the ASVs colored according to (A)
carrying the ASV. Black-filled circles indicate missing haplotypes.

\section{Bipartite Network, Specialization, and Modularity}

The bipartite interaction networks (Figure 4; Supplementary Figure 1) clearly depict ASVs 1 and 2 as the main photobionts of the Ramalina decipiens group. Ramalina sp. 1 is the only species not associated with these ASVs. This is most probably due to the poor representation of this species in the dataset. Excluding Ramalina sp. 1, whose only thallus associates with another ASV belonging to Trebouxia sp. TR9, specialization $\left(d^{\prime}\right)$ based on rarefied reads varied from 0.98 in Ramalina delicata to 0.51 in Ramalina maderensis. Species degree varied from 37 in Ramalina decipiens to 4 in Ramalina erosa and ND varied from 0.56 in Ramalina decipiens to 0.06 in Ramalina erosa. Species degree and ND were highest in the two most sampled species ( $R$. decipiens and $R$. maderensis). Specialization parameters obtained from the data non considering read counts returned similar results for species degree and $\mathrm{ND}$, but overall lower values of $d$, that ranged from 0.59 in $R$. erosa to 0.27 in $R$. decipiens. All specialization parameters are summarized in Table 3. The network based on rarefied reads was significantly modular $(Q=0.18, z$-score $=24.75$, value of $p<0.001$ ), and detected the presence of six modules (Figure 5). The modularity analyses of the second network resulted in a non-modular pattern $(Q=0.21, z$-score $=-0.68$, value of $p=0.241)$. The modular structure recovered in the first analysis seems to be a consequence of the mycobiont species distributions inasmuch as the geographic distances between and within modules were significantly different $\left(F=7.98, R^{2}=0.17, p<0.001\right)$.

\section{Genetic Diversity Statistics}

Nucleotide diversity $(\pi)$ and haplotype diversity $(H d)$ were calculated at the island and species levels (Figure 6). At the island level, $\pi$ ranged from 0.036 in Tenerife to 0.096 in Sal. $H d$ values ranged from 0.678 in Porto Santo to 0.928 in Fuerteventura. On average, Cape Verde had the highest $\pi$ value (0.092) followed by Madeira (0.060) and the Canary Islands (0.052). Regarding $H d$, Cape Verde again showed the highest value (0.810), followed by the Canary Islands (0.803) and Madeira (0.730). At the species level, $\pi$ values ranged from 0.014 in Ramalina hamulosa to 0.077 in Ramalina papyracea. $H d$ values ranged from 0.709 in Ramalina erosa to 0.905 in Ramalina pluviariae.

\section{Phylogenetic Signal}

The parameters $d$ ', species degree, and ND derived from both networks were not phylogenetically structured according to Pagel's $\lambda$ and Blomberg's $K$. Regarding genetic diversity, neither $\pi$ nor $H d$ were phylogenetically structured either. Phylogenetic signal statistics are summarized in Table 4.

\section{DISCUSSION}

We explored the role of the photosynthetic partners in the radiation of a clade of symbiotic organisms. According to our knowledge, this is the first time that the trophic niche is analyzed within the evolutionary framework of an island radiation in 
TABLE 1 | $p$-values of two-way ANOVA and Kruskal-Wallis test exploring the effect of island and/or mycobiont species on the frequency of each ASV.

\begin{tabular}{|c|c|c|c|}
\hline ASV & $P$ species & $P$ island & $P$ species*island \\
\hline ASV 1 & 0.8864 & $0.0028 * *$ & 0.4886 \\
\hline ASV 2 & 0.2556 & 0.4255 & 0.2016 \\
\hline ASV 3 & 0.5121 & 0.0803 & 0.7751 \\
\hline ASV 4 & 0.0831 & 0.9234 & 0.9996 \\
\hline ASV 5 & 0.5794 & 4.73E-14*** & - \\
\hline ASV 6 & 0.9861 & 0.1584 & 0.3857 \\
\hline ASV 7 & 0.6763 & $6.17 \mathrm{E}-12 * * *$ & - \\
\hline ASV 8 & 0.5544 & 0.8430 & 0.6702 \\
\hline ASV 9 & 0.1188 & $0.0007 * * *$ & 2.85E-12*** \\
\hline ASV 10 & 0.9892 & 0.4981 & 0.6184 \\
\hline ASV 11 & 0.9162 & $6.26 \mathrm{E}-08 * * *$ & - \\
\hline ASV 13 & 0.9886 & 0.9360 & 0.9964 \\
\hline ASV 19 & 0.5398 & 0.0879 & 0.9068 \\
\hline ASV 21 & $1.25 \mathrm{E}-03 * * *$ & $0.0011 * *$ & - \\
\hline ASV 23 & 0.8087 & 0.1121 & 0.9435 \\
\hline ASV 28 & 0.1180 & 0.9886 & 0.9997 \\
\hline ASV 29 & 0.9410 & 0.1643 & 0.5964 \\
\hline ASV 35 & 0.9788 & 0.9284 & 0.9924 \\
\hline ASV 36 & $0.0125 *$ & 0.6126 & 0.3036 \\
\hline ASV 38 & 0.7826 & 0.2845 & 0.2359 \\
\hline ASV 42 & $1.12 \mathrm{E}-02 * * *$ & 0.8119 & - \\
\hline ASV 43 & 0.0909 & $0.0006 * * *$ & - \\
\hline ASV 47 & 1.0000 & 0.4689 & 0.9905 \\
\hline ASV 49 & 0.9996 & $0.0105 * *$ & 0.9507 \\
\hline ASV 54 & 0.9831 & 0.2656 & 0.5889 \\
\hline
\end{tabular}

ASVs lacking the island-species interaction are those who did not meet the assumptions necessary to perform a two-way ANOVA. Bold values are statistically significant. $*<0.05 ; * *<0.01 ; * * *<0.001$.

lichen-forming fungi. We found no differences in the identity of the photobionts associated with the species of the $R$. decipiens group. The vast majority of specimens analyzed contained as their main photobiont one of the two most abundant ASVs, both belonging to Trebouxia sp. TR9. The frequency of both ASVs does not differ among Ramalina species, and we have indistinctly found both acting as major photobionts in thalli collected from the same locality on multiple occasions. The prevalence of T. sp. TR9 as main photobiont is not exclusive of the $R$. decipiens group. It was found in Macaronesian specimens of $R$. farinacea using Sanger sequencing (del Campo et al., 2013) and NGS (Molins et al., 2021). BLAST searches of the two predominant ASVs revealed their presence also in other genera. Both appear in Protoparmelia montagnei thalli in southern Spain (Singh et al., 2017) while ASV2 additionally appears in Lecanographa amylacea thalli in Poland and Sweden (Ertz et al., 2018). The fact that T. sp. TR9 is the main photobiont of Ramalina species in Macaronesia is congruent with our current knowledge of its physiology. Casano et al. (2011) showed that T. sp. TR9 grew faster and had better photosynthesis performance in in vitro experiments under relatively high temperatures and irradiances than $T$. jamesii, the main photobiont of $R$. farinacea thalli in the Iberian Peninsula (del Campo et al., 2013; Molins et al., 2021). The presence of both ASVs in southern Spain (Singh et al., 2017) also seems to point to the fact that this species can cope with higher temperature and light intensity given the similarity of that locality to those in which the $R$. decipiens group species occur in Macaronesia. Surprisingly, the records from Poland and

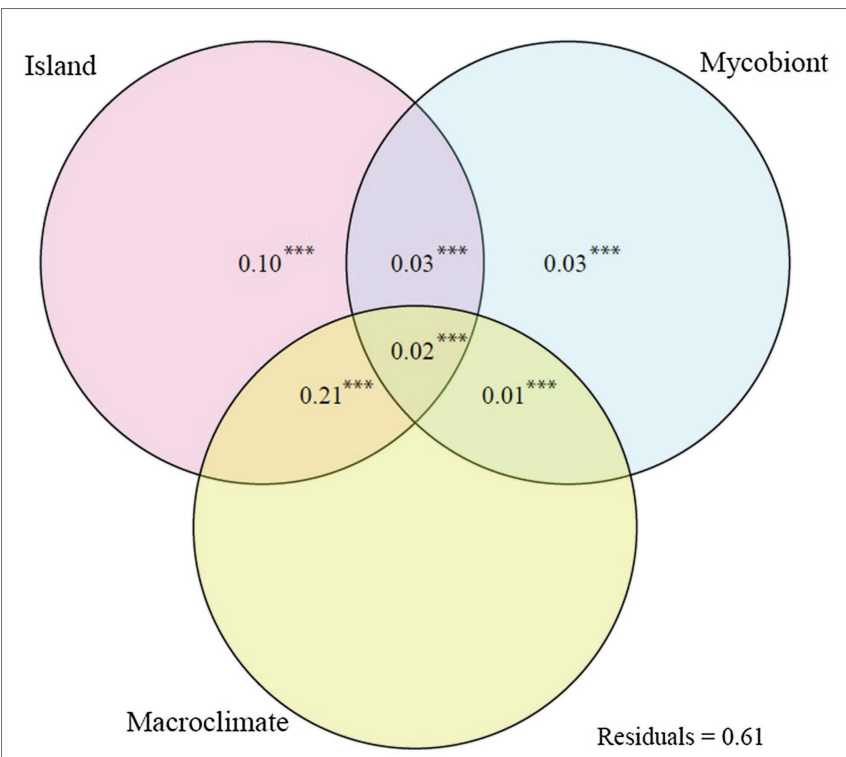

FIGURE 3 | Venn diagram showing variance partitioning between the simple and combined effects of the explanatory variables of the dbRDA (island, mycobiont identity, and macroclimate) and their mixed effects. The explained variation indicated are the adjusted $R^{2}$ values. Values $<0$ not shown. ${ }^{\star * \star} p<0.001$.

Sweden occurred in localities with radically different climatic conditions (Ertz et al., 2018). Lichen photobionts can show different physiologies even when they are phylogenetically very close (Sadowsky et al., 2016). The presence of ASV2, but not ASV1, in climatically divergent localities, such as the Białowieża Primeval forest in Poland or the island of Gotland in Sweden (Ertz et al., 2018), might suggest that they have differences in ecophysiological adaptations. Their presence in thalli collected in a same locality could be reflecting climatic differences at the microsite scale, as we have detected differences up to $4^{\circ} \mathrm{C}$ in two rocky outcrops separated by only $200 \mathrm{~m}$ (data not shown). The existence of such physiological differences will be explored in a forthcoming study.

We did not find differences in photobiont dominance between mycobiont species either. We detected algal co-occurrence in c. $50 \%$ of the studied thalli, a phenomenon reported in different lineages of lichen-forming fungi (Blaha et al., 2006; PierceyNormore, 2006; del Campo et al., 2010; Muggia et al., 2014; Rolshausen et al., 2018). Casano et al. (2011) showed that the two Trebouxia species detected in R. farinacea apparently displayed complementary physiological behaviors, arguing that algal co-occurrence in this species could have allowed it to expand its geographical range. However, most photobiont co-occurrence reports have been based on Sanger sequencing, so the relative abundance of each photobiont could not be assessed. Recently, Molins et al. (2021) revisited photobiont diversity in $R$. farinacea with NGS data showing that in c. $70 \%$ of all thalli one Trebouxia species was dominant. Paul et al. (2018) reported similar results for Umbilicaria hispanica and U. pustulata, with the main photobiont being represented by at least $80 \%$ of the reads in c. $80 \%$ of all thalli. In our study, this proportion is even more pronounced, with the main photobiont being dominant in $94 \%$ 
TABLE 2 | Summary of algal coexistence across Ramalina species.

\begin{tabular}{|c|c|c|c|c|c|c|c|}
\hline Species & $\mathbf{N}^{\circ}$ thalli & $\%$ thalli $>1$ ASV & $\begin{array}{l}\text { Mean ASV } \\
\text { count/thallus }\end{array}$ & $\begin{array}{l}\text { Maximum } n^{\circ} \\
\text { ASV/thallus }\end{array}$ & $\begin{array}{c}\text { Minimum \% main } \\
\text { photobiont }\end{array}$ & $\begin{array}{c}\text { Mean \% main } \\
\text { photobiont }\end{array}$ & $\begin{array}{c}\text { Max \% main } \\
\text { photobiont }\end{array}$ \\
\hline Ramalina decipiens & 57 & $60 \%$ & 2.46 & 9 & $42.93 \%$ & $93.85 \%$ & $99.94 \%$ \\
\hline Ramalina delicata & 3 & $33 \%$ & 2.33 & 5 & $95.89 \%$ & $95.89 \%$ & $95.89 \%$ \\
\hline Ramalina erosa & 9 & $22 \%$ & 1.22 & 2 & $67.04 \%$ & $83.50 \%$ & $99.96 \%$ \\
\hline Ramalina fortunata & 8 & $38 \%$ & 1.38 & 2 & $99.59 \%$ & $99.81 \%$ & $99.95 \%$ \\
\hline Ramalina gomerana & 3 & $33 \%$ & 3 & 7 & $85.78 \%$ & $85.78 \%$ & $85.78 \%$ \\
\hline Ramalina hamulosa & 10 & $30 \%$ & 1.3 & 2 & $95.84 \%$ & $97.99 \%$ & $99.81 \%$ \\
\hline Ramalina maderensis & 57 & $53 \%$ & 2.23 & 10 & $54.28 \%$ & $93.74 \%$ & $99.98 \%$ \\
\hline Ramalina nematodes & 6 & $50 \%$ & 2 & 5 & $90.28 \%$ & $96.63 \%$ & $99.87 \%$ \\
\hline Ramalina papyracea & 6 & $50 \%$ & 2 & 4 & $96.19 \%$ & $98.33 \%$ & $99.63 \%$ \\
\hline Ramalina pluviariae & 6 & $100 \%$ & 4.67 & 7 & $83.74 \%$ & $93.73 \%$ & $99.79 \%$ \\
\hline Ramalina portosantana & 8 & $50 \%$ & 2 & 5 & $88.48 \%$ & $94.70 \%$ & $99.95 \%$ \\
\hline Ramalina sabinosae & 4 & $100 \%$ & 2.25 & 3 & $80.00 \%$ & $94.22 \%$ & $99.75 \%$ \\
\hline Ramalina sampaiana & 13 & $38 \%$ & 1.92 & 6 & $69.96 \%$ & $90.89 \%$ & $98.60 \%$ \\
\hline Ramalina sp. 1 & 1 & $0 \%$ & 1 & 1 & - & - & - \\
\hline Ramalina sp. 2 & 6 & $50 \%$ & 1.5 & 2 & $99.85 \%$ & $99.89 \%$ & $99.96 \%$ \\
\hline
\end{tabular}

Number of studied thalli, percentage of thalli that showed algal coexistence, minimum, mean, and maximum number of ASVs per thallus and minimum, mean, and maximum relative abundance of the main photobiont across thalli showing algal coexistence.

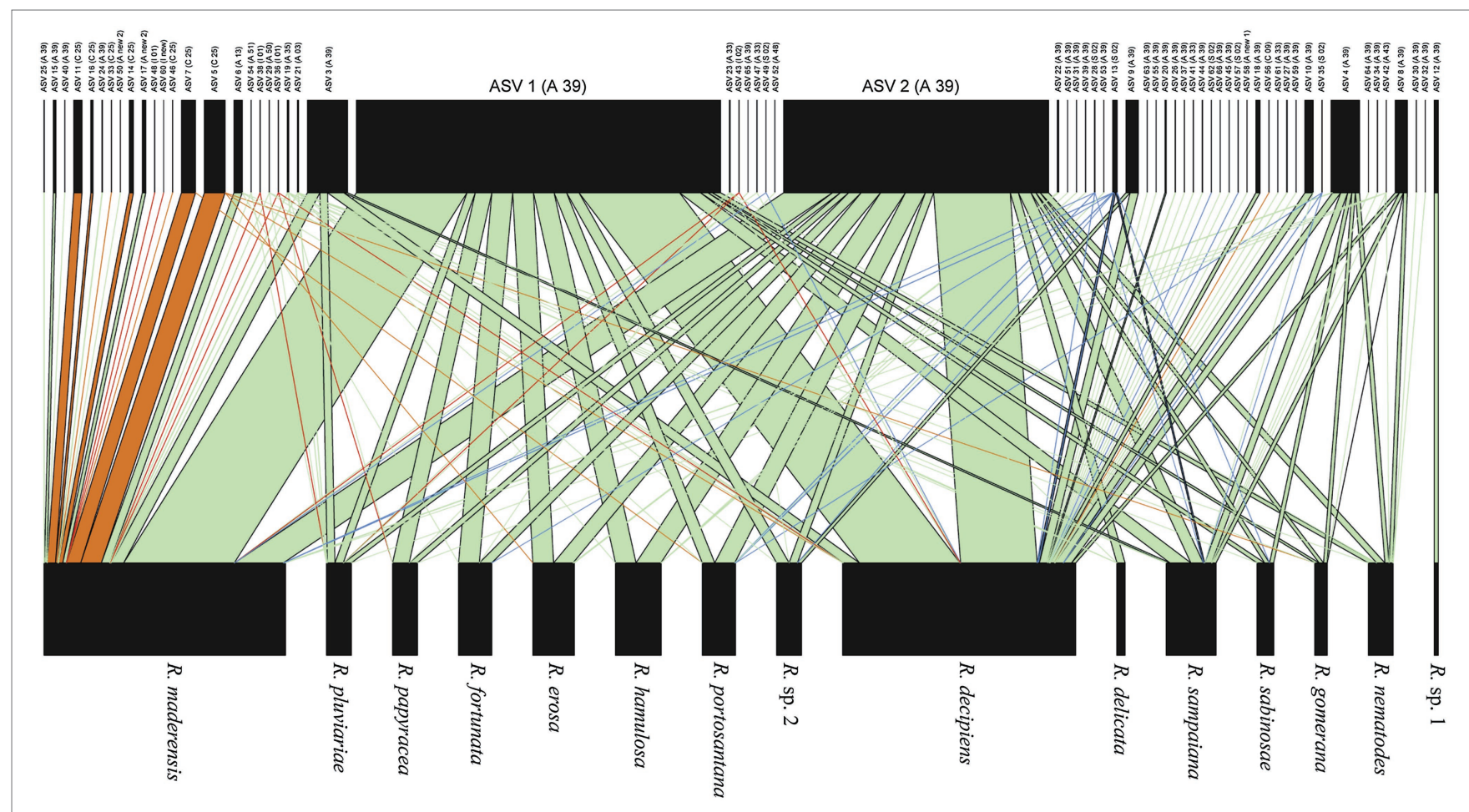

FIGURE 4 | Bipartite network based on rarefied reads showing interactions between Ramalina species and Trebouxia ASVs. Interactions with ASVs belonging to Trebouxia clades A, C, I, and S are depicted in green, orange, red and blue, respectively. Width of the links is proportional to the frequency of the association.

of the thalli showing algal co-occurrence. The overwhelming dominance of the main photobiont over the rest sheds doubt on the ecological importance of algal co-occurrence. Photobiont co-occurrence has been studied more in-depth in coraldinoflagellate symbioses. Young corals establish symbiosis with a subset of the photobionts available in their environment (Poland et al., 2013; Yamashita et al., 2013). This first photobiont community is restructured in response to environmental heterogeneity (Rowan, 2004) or other processes, such as re-establishment of photobiont communities after a previous stress-induced loss (Jones et al., 2008). After the restructuration process, adult corals usually end up with a single Symbiodiniaceae lineage dominating the photobiont community (Parkinson and Baums, 2014). This agrees with the results shown by Molins et al. (2021) for Ramalina farinacea in which young and old thalli showed different microalgal communities, more diverse in young thalli.

The community structure of the photobionts associated to species of the $R$. decipiens group is chiefly explained by the 
TABLE 3 | Summary of specialization parameters of the bipartite networks based on the sum of the rarefied reads of the thalli of each species and the conversion of the abundance of ITS2 reads of the thalli to presence-absence data.

\begin{tabular}{|c|c|c|c|c|c|c|}
\hline \multirow[b]{2}{*}{ Mycobiont species } & \multicolumn{3}{|c|}{ Rarefied reads network } & \multicolumn{3}{|c|}{ Presence-absence network } \\
\hline & $d^{\prime}$ & Species degree & $N D$ & $d^{\prime}$ & Species degree & $N D$ \\
\hline Ramalina decipiens & 0.54 & 37 & 0.56 & 0.28 & 38 & 0.58 \\
\hline Ramalina delicata & 0.98 & 5 & 0.08 & 0.46 & 5 & 0.08 \\
\hline Ramalina erosa & 0.68 & 4 & 0.06 & 0.59 & 4 & 0.06 \\
\hline Ramalina fortunata & 0.72 & 5 & 0.08 & 0.54 & 5 & 0.08 \\
\hline Ramalina gomerana & 0.56 & 7 & 0.11 & 0.38 & 7 & 0.11 \\
\hline Ramalina hamulosa & 0.70 & 6 & 0.09 & 0.53 & 6 & 0.09 \\
\hline Ramalina maderensis & 0.51 & 33 & 0.50 & 0.29 & 33 & 0.50 \\
\hline Ramalina nematodes & 0.51 & 9 & 0.14 & 0.33 & 9 & 0.14 \\
\hline Ramalina papyracea & 0.74 & 6 & 0.09 & 0.46 & 6 & 0.09 \\
\hline Ramalina pluviariae & 0.54 & 12 & 0.18 & 0.31 & 12 & 0.18 \\
\hline Ramalina portosantana & 0.70 & 8 & 0.12 & 0.41 & 8 & 0.12 \\
\hline Ramalina sabinosae & 0.58 & 5 & 0.08 & 0.42 & 6 & 0.09 \\
\hline Ramalina sampaiana & 0.51 & 14 & 0.21 & 0.33 & 14 & 0.21 \\
\hline Ramalina sp. 1 & 0.62 & 6 & 0.09 & 0.44 & 6 & 0.09 \\
\hline Ramalina sp. 2 & 1.00 & 1 & 0.02 & 1.00 & 1 & 0.02 \\
\hline
\end{tabular}

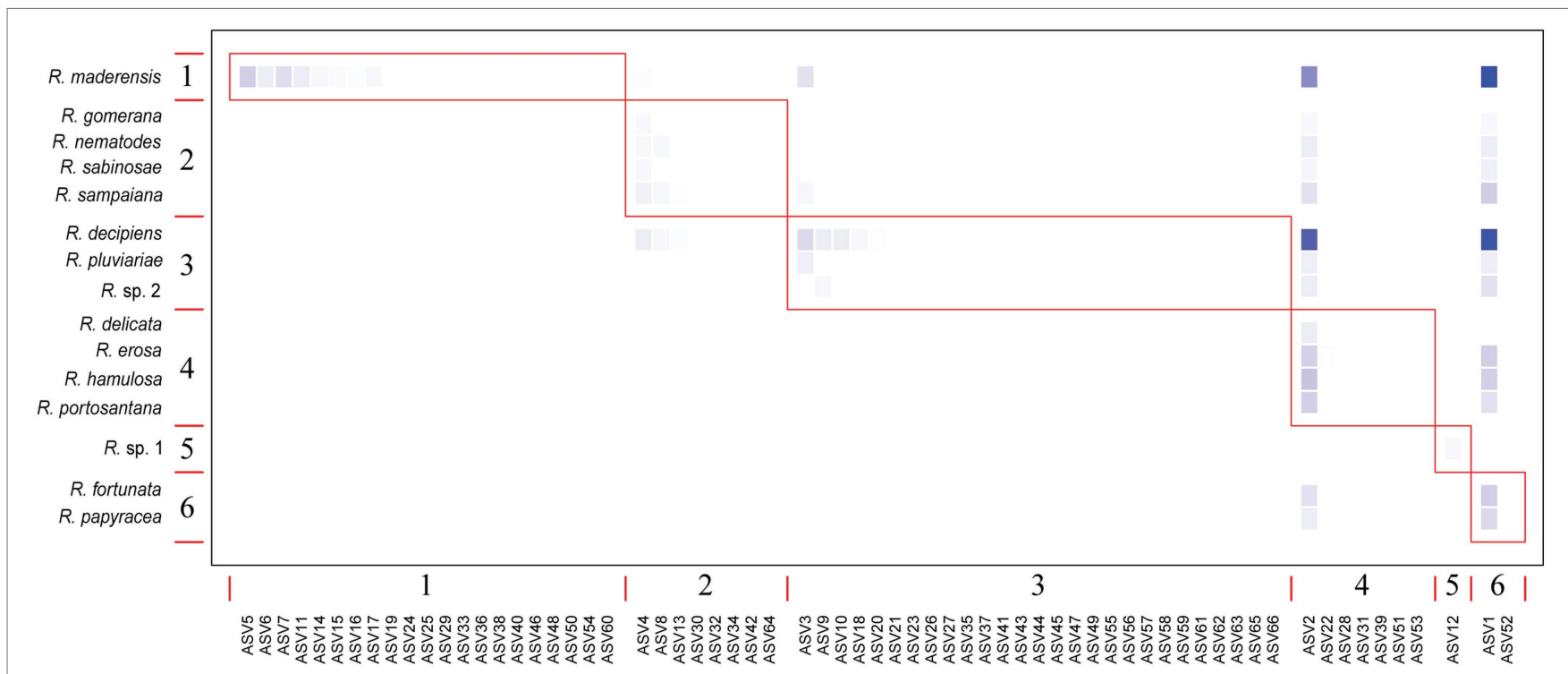

FIGURE 5 | Modularity plot featuring the six modules identified by the Becket algorithm $(Q=0.179, z$-score $=709.31$; value of $p<0.001)$ in the rarefied reads network. Taxa are sorted according to their modular affinity, mycobiont species as rows, and photobiont ASVs as columns. Red boxes delineate the six modules. Color intensity is proportional to the relative abundance of each ASV per mycobiont species.

interaction between island and macroclimate, mycobiont identity being only of marginal importance. This finding agrees with previous studies that have reported macroclimate as a major driver of genetic variation of photobionts (Beiggi and Piercey-Normore, 2007; Nelsen and Gargas, 2009; Fernández-Mendoza et al., 2011; Leavitt et al., 2016; Magain et al., 2017). Other studies, however, have suggested a greater importance of mycobiont identity (Buckley et al., 2014; Leavitt et al., 2015; Vančurová et al., 2018; Jüriado et al., 2019). The relative importance of both factors can be influenced by the scale of the study. For instance, Pino-Bodas and Stenroos (2021) studied the diversity of the photobionts associated with the genus Cladonia by Sanger sequencing of the ITS and actin type I genes and found that the relative importance of the different factors differed between the two genes. However, when the ITS dataset was trimmed to include only the specimens for which actin type I sequences were available (losing mycobiont species in the process) the results for both datasets were similar (Pino-Bodas and Stenroos, 2021). The importance of the islandmacroclimate interaction in our study is congruent with the climatic heterogeneity of Macaronesia, as the different islands show marked differences in the vegetation assemblages they harbor (del Arco Aguilar and Rodríguez Delgado, 2018) but at the same time, due to their pronounced orography, close areas can experience radically different climatic conditions (Sánchez-Benítez et al., 2017).

We found no phylogenetic signal in either the specialization parameter $d$ ' or the genetic diversity indices tested, suggesting that species specialization toward their photobionts is not an evolutionarily conserved trait. Magain et al. (2017) studied 

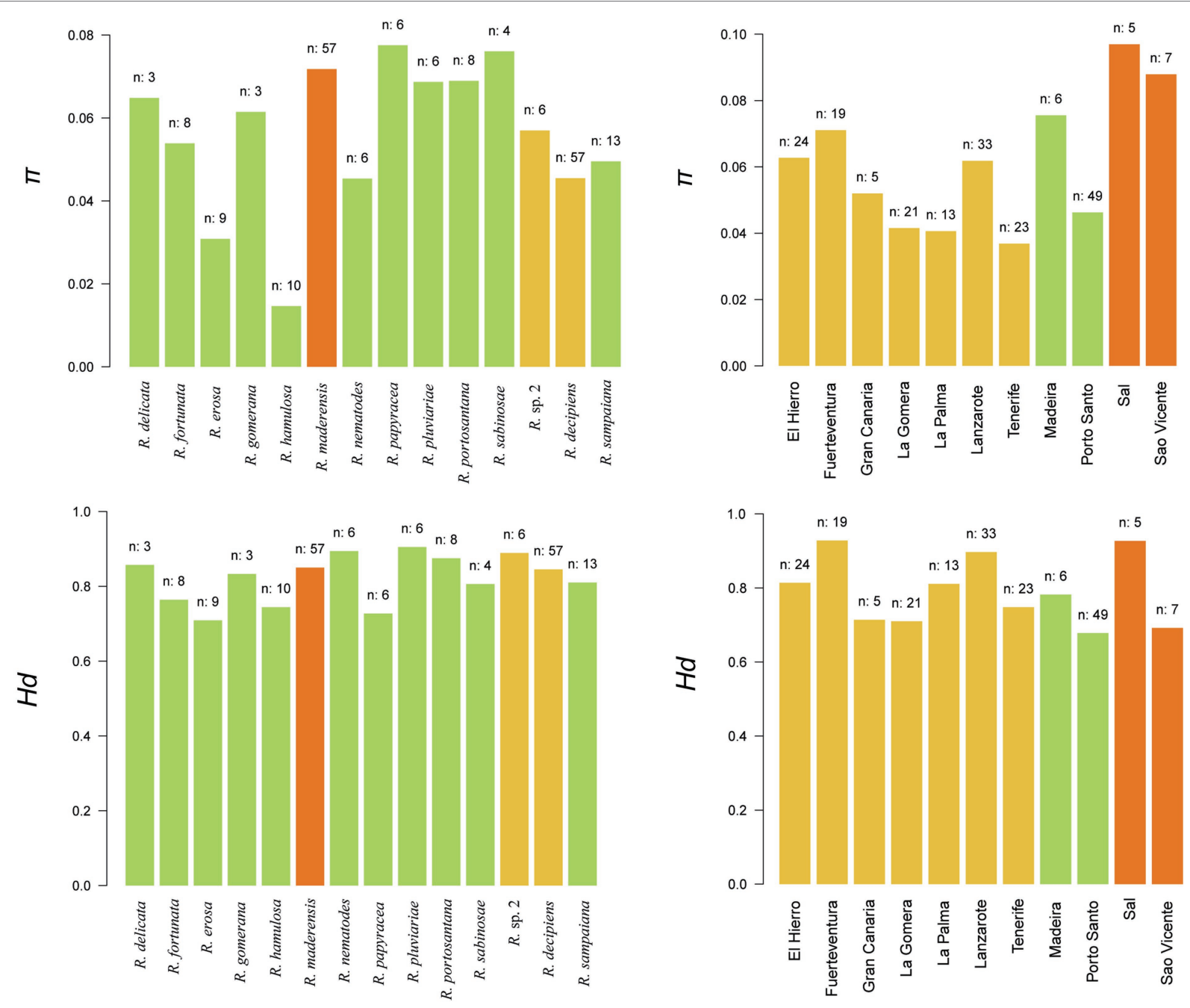

FIGURE 6 | Diversity statistics. Upper and lower panels represent nucleotide $(\pi)$ and haplotype (Hd) diversities at the species (left) and island (right) levels. Species plots are colored by the number of archipelagos in which the species is present: green (one), yellow (two), and orange (three). Island plots are colored by archipelago: yellow (Canarian archipelago), green (Madeira archipelago), and orange (Cape Verde archipelago). The number of samples by which the island or species is represented in the dataset appears on top of each bar.

TABLE 4 | Summary of phylogenetic signal statistics.

\begin{tabular}{lcccc}
\hline & $\lambda$ & value of $\boldsymbol{p}(\boldsymbol{\lambda})$ & $\boldsymbol{K}$ & value of $\boldsymbol{p}(\boldsymbol{K})$ \\
\hline $\begin{array}{l}\text { d' (rarefied reads } \\
\text { network) }\end{array}$ & 0.716 & 0.535 & 0.771 & 0.183 \\
$\begin{array}{l}\text { Species degree (rarefied } \\
\text { reads network) }\end{array}$ & 0.257 & 0.634 & 0.734 & 0.227 \\
$\begin{array}{l}\text { ND (rarefied reads } \\
\text { network) }\end{array}$ & 0.257 & 0.634 & 0.734 & 0.218 \\
$\begin{array}{l}\text { d' (presence-absence } \\
\text { network) }\end{array}$ & 0.000 & 1.000 & 0.596 & 0.163 \\
$\begin{array}{l}\text { Species degree } \\
\text { (presence-absence }\end{array}$ & 0.237 & 0.665 & 0.735 & 0.209 \\
network) & & & & \\
$\begin{array}{l}\text { ND (presence-absence } \\
\text { network) }\end{array}$ & 0.237 & 0.665 & 0.735 & 0.227 \\
$\pi$ & & & & \\
Hd & 0 & 1 & 0.414 & 0.631 \\
& 0 & 0.423 & 0.616
\end{tabular}

patterns of mycobiont specialization toward their cyanobionts in the Peltigera section Polydactylon. They found that generalist and specialist species were distributed all over the phylogeny proposing that photobiont specialization by lichen-forming fungi does not equal to an evolutionary dead-end as it has been proposed for other organisms (e.g., Haldane, 1951; Nosil and Mooers, 2005). Similar results of no phylogenetic conservatism in mycobiont specialization toward photobionts have been recently reported by Pino-Bodas and Stenroos (2021) for the genus Cladonia. Our results suggest that the $R$. decipiens group species associate with locally adapted photobionts, as do other lichenforming fungi (Blaha et al., 2006; Muggia et al., 2014; Rolshausen et al., 2018). This is particularly clear in $R$. maderensis, the only species of the group occurring in the Cape Verde archipelago. In Cape Verde, $R$. maderensis has performed a photobiont switch and associates predominantly with ASVs belonging to Trebouxia 
C25. Trebouxia C25 has only been found previously in Parmotrema aldabrense thalli in Kenya, in a locality near the coast (Muggia et al., 2020). Nothing is known about this species physiology but the fact that it occurs mainly in tropical regions as well as all other clade C Trebouxia species in Muggia et al. (2020), could be indicative of a physiology adapted to higher temperatures and light intensities than those in which T. sp. TR9 thrives.

We have not observed differences neither in identity nor in the abundance of ITS2 reads in the photobionts associating with the different species of the $R$. decipiens group. Because differences in identity can be linked with differentiated growth rates and photosynthetic performances at the species (Casano et al., 2011) and strain (Determeyer-Wiedmann et al., 2019; Aigner et al., 2020) levels, we conclude that a partitioning of the trophic niche has probably not occurred during the $R$. decipiens group radiation. This fact, coupled with the marginal importance of mycobiont species on photobiont community structure and the geographic structure underlying the bipartite network modules, suggests that the photobionts are not a factor driving the $R$. decipiens group diversification. A segregation of the trophic niche is a key driver of adaptive radiation in many other examples, such as the Darwin finches (Grant and Grant, 2008), East African cichlid fishes (Danley and Kocher, 2001), Tylomelania freshwater gastropods (Rintelen et al., 2004), Cyprinodon pupfishes (Martin and Feinstein, 2014), Tetragnatha spiders (Kennedy et al., 2019), and many others (Gillespie et al., 2020). However trophic niche differentiation is not the only factor that can explain adaptive radiation. It has been hypothesized that Hawaiian lobeliads have diversified physiologically across environments differing in a key resource (i.e., light, Montgomery and Givnish, 2008). Recently it has been proposed (Gillespie et al., 2020) that symbiotic interactions with microbes could facilitate adaptive radiation. Physiological speciation in the $R$. decipiens group and a study of the species associated microbiomes will be explored in forthcoming works.

\section{CONCLUSION}

We have found no evidence for trophic niche segregation in the context of the diversification of the Macaronesian endemic species of the $R$. decipiens group. They do not differ neither in the identity nor in the abundance of their photobionts. Thus, we argue that the photobionts are not a key factor driving speciation in the group. Instead, Ramalina species appear to associate with locally adapted Trebouxia. Algal coexistence was common, but the contribution of the secondary photobionts was marginal in most thalli. This opens new questions about the ecological importance of algal coexistence.

\section{REFERENCES}

Aigner, S., Glaser, K., Arc, E., Holzinger, A., Schletter, M., Karsten, U., et al. (2020). Adaptation to aquatic and terrestrial environments in Chlorella vulgaris (Chlorophyta). Front. Microbiol. 11:585836. doi: 10.3389/fmicb.2020.585836

Álvarez, R., Del Hoyo, A., Díaz-Rodríguez, C., Coello, A. J., Del Campo, E. M., Barreno, E., et al. (2015). Lichen rehydration in heavy metal-polluted environments: $\mathrm{Pb}$ modulates the oxidative response of both Ramalina farinacea

\section{DATA AVAILABILITY STATEMENT}

The datasets presented in this study can be found in online repositories. The names of the repository/repositories and accession number(s) can be found in the article/ Supplementary Material.

\section{AUTHOR CONTRIBUTIONS}

SP-O, FG, IP-V, and MB designed the study. MB, IP-V, and SP-O organized the fieldwork, research permits, and collected the specimens. $\mathrm{MB}$ and $\mathrm{LH}-\mathrm{M}$ performed the laboratory work. MB analyzed the data and wrote the manuscript. All authors contributed to the article and approved the submitted version.

\section{FUNDING}

This study was financed by grant CGL2016-81136-P from the Spanish Ministry of Science and Innovation. MB was supported by grant BES-2017-081807. SP-O was supported by the grant RYC-2014-16 784 from the Spanish Ministry of Economy, Industry and Competitiveness.

\section{ACKNOWLEDGMENTS}

We thank Emilio Cano and David Monjas for their advice on technical issues. We also want to thank the CSIC Unit of Information Resources for Research (URICI) for its support of the publication fee by the Open Access Publication Support Program. We also thank two reviewers for their help in improving the manuscript.

\section{SUPPLEMENTARY MATERIAL}

The Supplementary Material for this article can be found online at: https://www.frontiersin.org/articles/10.3389/fmicb.2021.784182/ full\#supplementary-material

SUPPLEMENTARY FIGURE 1 | Bipartite network based on presence-absence data showing interactions between Ramalina species and Trebouxia ASVs. Interactions with ASVs belonging to Trebouxia clades A, C, I, and S are depicted in green, orange, red and blue, respectively. Width of the links is proportional to the frequency of the association.

thalli and its isolated microalgae. Microb. Ecol. 69, 698-709. doi: 10.1007/ s00248-014-0524-0

Aptroot, A. (2008). Lichens of St Helena and Ascension Island. Bot. J. Linn. Soc. 158, 147-171. doi: 10.1111/j.1095-8339.2008.00797.x

Beckett, S. J. (2016). Improved community detection in weighted bipartite networks. R. Soc. Open Sci. 3:140536. doi: 10.1098/rsos.140536

Beiggi, S., and Piercey-Normore, M. D. (2007). Evolution of ITS ribosomal RNA secondary structures in fungal and algal symbionts of selected species 
of Cladonia sect. Cladonia (Cladoniaceae, Ascomycotina). J. Mol. Evol. 64, 528-542. doi: 10.1007/s00239-006-0115-x

Blaha, J., Baloch, E., and Grube, M. (2006). High photobiont diversity associated with the euryoecious lichen-forming ascomycete Lecanora rupicola (Lecanoraceae, Ascomycota). Biol. J. Linn. Soc. 88, 283-293. doi: 10.1111/j.1095-8312.2006.00640.x

Blanchon, D. J., Braggins, J. E., and Stewart, A. (1996). The lichen genus Ramalina in New Zealand. J. Hattori Bot. Lab. 79, 43-98.

Blomberg, S. P., Garland, T., and Ives, A. R. (2003). Testing for phylogenetic signal in comparative data: behavioral traits are more labile. Evolution 57, 717-745. doi: 10.1111/j.0014-3820.2003.tb00285.x

Blüthgen, N., Menzel, F., and Blüthgen, N. (2006). Measuring specialization in species interaction networks. BMC Ecol. 6:9. doi: 10.1186/1472-6785-6-9

Bowler, P., and Rundel, P. W. (1972). Ramalina bajacalifornica, a new species of lichen from Baja California. Bryologist 75, 365-368. doi: 10.2307/3241479

Bowler, P., and Rundel, P. W. (1973). Two new lichens (Ramalina) from Baja California, Mexico. Bryologist 76, 211-213. doi: 10.2307/3241251

Buckley, H. L., Rafat, A., Ridden, J. D., Cruickshank, R. H., Ridgway, H. J., and Paterson, A. M. (2014). Phylogenetic congruence of lichenized fungi and algae is affected by spatial scale and taxonomic diversity. PeerJ 2:e573. doi: $10.7717 /$ peerj. 573

Callahan, B. J., McMurdie, P. J., and Holmes, S. P. (2017). Exact sequence variants should replace operational taxonomic units in marker-gene data analysis. ISME J. 11, 2639-2643. doi: 10.1038/ismej.2017.119

Callahan, B. J., McMurdie, P. J., Rosen, M. J., Han, A. W., Johnson, A. J. A., and Holmes, S. P. (2016). DADA2: high-resolution sample inference from Illumina amplicon data. Nat. Methods 13, 581-583. doi: 10.1038/nmeth.3869

Casano, L. M., del Campo, E. M., García-Breijo, F. J., Reig-Armiñana, J., Gasulla, F., Del Hoyo, A., et al. (2011). Two Trebouxia algae with different physiological performances are ever-present in lichen thalli of Ramalina farinacea. Coexistence versus competition? Environ. Microbiol. 13, 806-818. doi: $10.1111 /$ j.1462-2920.2010.02386.x

Dal Grande, F., Rolshausen, G., Divakar, P. K., Crespo, A., Otte, J., Schleuning, M., et al. (2018). Environment and host identity structure communities of green algal symbionts in lichens. New Phytol. 217, 277-289. doi: 10.1111/nph.14770

Danley, P. D., and Kocher, T. D. (2001). Speciation in rapidly diverging systems: lessons from Lake Malawi. Mol. Ecol. 10, 1075-1086. doi: 10.1046/j.1365-294X.2001.01283.x

del Arco Aguilar, M. J., and Rodríguez Delgado, O. (2018). Vegetation of the Canary Islands. Princeton: Springer, New York.

del Campo, E. M., Catalá, S., Gimeno, J., del Hoyo, A., Martínez-Alberola, F., Casano, L. M., et al. (2013). The genetic structure of the cosmopolitan threepartner lichen Ramalina farinacea evidences the concerted diversification of symbionts. FEMS Microbiol. Ecol. 83, 310-323. doi: 10.1111/j.1574-6941.2012.01474.x

del Campo, E. M., Gimeno, J., De Nova, J. P. G., Casano, L. M., Gasulla, F., García-Breijo, F., et al. (2010). South European populations of Ramalina farinacea (L.) Ach. Share different Trebouxia algae. Bibl. Lichenol. 105, 247-256.

del Hoyo, A., Alvarez, R., del Campo, E. M., Gasulla, F., Barreno, E., and Casano, L. M. (2011). Oxidative stress induces distinct physiological responses in the two Trebouxia phycobionts of the lichen Ramalina farinacea. Ann. Bot. 107, 109-118. doi: 10.1093/aob/mcq206

Determeyer-Wiedmann, N., Sadowsky, A., Convey, P., and Ott, S. (2019). Physiological life history strategies of photobionts of lichen species from Antarctic and moderate European habitats in response to stressful conditions. Polar Biol. 42, 395-405. doi: 10.1007/s00300-018-2430-2

Dormann, C. F., Gruber, B., and Fründ, J. (2008). Introducing the bipartite package: analysing ecological networks. $R$ News $8,8-11$.

Ertz, D., Guzow-Krzemińska, B., Thor, G., Łubek, A., and Kukwa, M. (2018). Photobiont switching causes changes in the reproduction strategy and phenotypic dimorphism in the Arthoniomycetes. Sci. Rep. 8:4952. doi: 10.1038/s41598-018-23219-3

Fernández-Mendoza, F., Domaschke, S., García, M. A., Jordan, P., Martín, M. P., and Printzen, C. (2011). Population structure of mycobionts and photobionts of the widespread lichen Cetraria aculeata. Mol. Ecol. 20, 1208-1232. doi: 10.1111/j.1365-294X.2010.04993.x

Fick, S. E., and Hijmans, R. J. (2017). WorldClim 2: new 1-km spatial resolution climate surfaces for global land areas. Int. J. Climatol. 37, 4302-4315. doi: 10.1002/joc.5086

Friedl, T., and Büdel, B. (2008). "Photobionts" in Lichen Biology. ed. T. H. Nash (Cambridge: Cambridge University Press), 9.

Garrido-Benavent, I., Pérez-Ortega, S., and de los Ríos, A., (2017). From Alaska to Antarctica: species boundaries and genetic diversity of Prasiola
(Trebouxiophyceae), a foliose chlorophyte associated with the bipolar lichenforming fungus Mastodia tessellata. Mol. Phylogenet. Evol. 107, 117-131. doi: 10.1016/j.ympev.2016.10.013

Gaya, E., Fernández-Brime, S., Vargas, R., Lachlan, R. F., Gueidan, C., Ramírez-Mejía, M., et al. (2015). The adaptive radiation of lichen-forming Teloschistaceae is associated with sunscreening pigments and a bark-to-rock substrate shift. PNAS 112, 11600-11605. doi: 10.1073/pnas.1507072112

Gillespie, R. G., Bennett, G. M., De Meester, L., Feder, J. L., Fleischer, R. C., Harmon, L. J., et al. (2020). Comparing adaptive radiations across space, time, and taxa. J. Hered. 111, 1-20. doi: 10.1093/jhered/esz064

Gittenberger, E. (1991). What about non-adaptive radiation? Biol. J. Linn. Soc. 43, 263-272. doi: 10.1111/j.1095-8312.1991.tb00598.x

Givnish, T. J. (2015). Adaptive radiation versus 'radiation' and 'explosive diversification': why conceptual distinctions are fundamental to understanding evolution. New Phytol. 207, 297-303. doi: 10.1111/nph.13482

Gómez, J. M., Perfectti, F., Abdelaziz, M., Lorite, J., Muñoz-Pajares, A. J., and Valverde, J. (2015). Evolution of pollination niches in a generalist plant clade. New Phytol. 205, 440-453. doi: 10.1111/nph.13016

Gould, S. J., and Eldredge, N. (1977). Punctuated equilibria: the tempo and mode of evolution reconsidered. Paleobiology 3, 115-151. doi: 10.1017/S0094837300005224

Grant, P. R., and Grant, B. R. (2008). How and why Species Multiply Princeton University Press.

Haldane, J.B.S. 1951. Everything Has a History. Allen \& Unwin, London.

Hijmans, R. J., Van Etten, J., Cheng, J., Mattiuzzi, M., and Greenberg, J. A. (2015). Package 'raster.' R package 734.

Hijmans, R. J., Williams, E., Vennes, C., and Hijmans, M. R. C. (2017). Package 'geosphere.' Spherical Trigonometry 1.

Jones, A. M., Berkelmans, R., van Oppen, M. J. H., Mieog, J. C., and Sinclair, W. (2008). A community change in the algal endosymbionts of a scleractinian coral following a natural bleaching event: field evidence of acclimatization. Proc. R. Soc. B Biol. Sci. 275, 1359-1365. doi: 10.1098/rspb.2008.0069

Jüriado, I., Kaasalainen, U., Jylhä, M., and Rikkinen, J. (2019). Relationships between mycobiont identity, photobiont specificity and ecological preferences in the lichen genus Peltigera (Ascomycota) in Estonia (northeastern Europe). Fungal Ecol. 39, 45-54. doi: 10.1016/j.funeco.2018.11.005

Katoh, K., Misawa, K., Kuma, K., and Miyata, T. (2002). MAFFT: a novel method for rapid multiple sequence alignment based on fast Fourier transform. Nucleic Acids Res. 30, 3059-3066. doi: 10.1093/nar/gkf436

Kembel, S. W., Cowan, P. D., Helmus, M. R., Cornwell, W. K., Morlon, H., Ackerly, D. D., et al. (2010). Picante: R tools for integrating phylogenies and ecology. Bioinformatics 26, 1463-1464. doi: 10.1093/bioinformatics/btq166

Kennedy, S., Lim, J. Y., Clavel, J., Krehenwinkel, H., and Gillespie, R. G. (2019). Spider webs, stable isotopes and molecular gut content analysis: multiple lines of evidence support trophic niche differentiation in a community of Hawaiian spiders. Funct. Ecol. 33, 1722-1733. doi: 10.1111/1365-2435.13361

Kistenich, S., Timdal, E., Bendiksby, M., and Ekman, S. (2018). Molecular systematics and character evolution in the lichen family Ramalinaceae (Ascomycota: Lecanorales). Taxon 67, 871-904. doi: 10.12705/675.1

Krog, H. (1990). New Ramalina Species from Porto Santo, Madeira. Lichenologist 22, 241-247. doi: $10.1017 /$ S0024282990000263

Krog, H., and Østhagen, H. (1980a). The genus Ramalina in the Canary Islands. Nor. J. Bot. 27, 255-296.

Krog, H., and Østhagen, H. (1980b). Two new Ramalina species from Porto Santo, the Madeira Islands. Nor. J. Bot. 27, 185-188.

Krog, H., and Swinscow, T. D. V. (1976). The genus Ramalina in East Africa. Nor. J. Bot. 23, 153-175

Landis, M. J., Freyman, W. A., and Baldwin, B. G. (2018). Retracing the Hawaiian silversword radiation despite phylogenetic, biogeographic, and paleogeographic uncertainty. Evolution 72, 2343-2359. doi: 10.1111/evo.13594

Leavitt, S. D., Kraichak, E., Nelsen, M. P., Altermann, S., Divakar, P. K., Alors, D., et al. (2015). Fungal specificity and selectivity for algae play a major role in determining lichen partnerships across diverse ecogeographic regions in the lichen-forming family Parmeliaceae (Ascomycota). Mol. Ecol. 24, 3779-3797. doi: $10.1111 /$ mec.13271

Leavitt, S. D., Kraichak, E., Vondrak, J., Nelsen, M. P., Sohrabi, M., Perez-Ortega, S., et al. (2016). Cryptic diversity and symbiont interactions in rock-posy lichens. Mol. Phylogenet. Evol. 99, 261-274. doi: 10.1016/j.ympev.2016.03.030

Legendre, P., and Anderson, M. J. (1999). Distance-based redundancy analysis: testing multispecies responses in multifactorial ecological experiments. Ecol. 
Monogr. 69, 1-24. doi: 10.1890/0012-9615(1999)069[0001:DBRATM]2. $0 . \mathrm{CO} ; 2$

Leigh, J. W., and Bryant, D. (2015). Popart: full-feature software for haplotype network construction. Methods Ecol. Evol. 6, 1110-1116. doi: 10.1111/2041-210X.12410

Losos, J. B. (2009). Lizards in an Evolutionary Tree: Ecology and Adaptive Radiation of Anoles. Oakland: University of California Press.

Lücking, R., Hodkinson, B. P., and Leavitt, S. D. (2017). The 2016 classification of lichenized fungi in the Ascomycota and Basidiomycota - approaching one thousand genera. Bryologist 119, 361-416. doi: 10.1639/0007-2745-119.4.361

Lynch, M., and Crease, T. J. (1990). The analysis of population survey data on DNA sequence variation. Mol. Biol. Evol. 7, 377-394. doi: 10.1093/ oxfordjournals.molbev.a040607

Magain, N., Miadlikowska, J., Goffinet, B., Sérusiaux, E., and Lutzoni, F. (2017). Macroevolution of specificity in cyanolichens of the genus Peltigera section Polydactylon (Lecanoromycetes, Ascomycota). Syst. Biol. 66, 74-99. doi: 10.1093/sysbio/syw065

Mao, Y., Economo, E. P., and Satoh, N. (2018). The roles of introgression and climate change in the rise to dominance of Acropora corals. Curr. Biol. 28, 3373-3382.e5. doi: 10.1016/j.cub.2018.08.061

Marcano, V., Méndez, A. M., and Prü, E. P. (2021). The genus Ramalina Acharius (Ascomycota, Lecanoromycetes, Ramalinaceae) in northern South America. Phytotaxa 504, 1-77. doi: 10.11646/phytotaxa.504.1.1

Martin, C. H., and Feinstein, L. C. (2014). Novel trophic niches drive variable progress towards ecological speciation within an adaptive radiation of pupfishes. Mol. Ecol. 23, 1846-1862. doi: 10.1111/mec.12658

McMurdie, P. J., and Holmes, S. (2013). Phyloseq: an R package for reproducible interactive analysis and graphics of microbiome census data. PLoS One 8:e61217. doi: 10.1371/journal.pone.0061217

Miller, M. A., Pfeiffer, W., and Schwartz, T. (2011). "The CIPRES science gateway: a community resource for phylogenetic analyses." in Proceedings of the 2011 TeraGrid Conference: Extreme Digital Discovery TG'11. New York, NY, USA: Association for Computing Machinery. pp. 1-8.

Molins, A., Moya, P., Muggia, L., and Barreno, E. (2021). Thallus growth stage and geographic origin shape microalgal diversity in Ramalina farinacea lichen holobionts. J. Phycol. 57, 975-987. doi: 10.1111/jpy.13140

Montgomery, R. A., and Givnish, T. J. (2008). Adaptive radiation of photosynthetic physiology in the hawaiian lobeliads: dynamic photosynthetic responses. Oecologia 155, 455-467. doi: 10.1007/s00442-007-0936-3

Muggia, L., Nelsen, M. P., Kirika, P. M., Barreno, E., Beck, A., Lindgren, H., et al. (2020). Formally described species woefully underrepresent phylogenetic diversity in the common lichen photobiont genus Trebouxia (Trebouxiophyceae, Chlorophyta): An impetus for developing an integrated taxonomy. Mol. Phylogenet. Evol. 149:106821. doi: 10.1016/j.ympev.2020.106821

Muggia, L., Pérez-Ortega, S., Kopun, T., Zellnig, G., and Grube, M. (2014). Photobiont selectivity leads to ecological tolerance and evolutionary divergence in a polymorphic complex of lichenized fungi. Ann. Bot. 114, 463-475. doi: $10.1093 / \mathrm{aob} / \mathrm{mcu} 146$

Muggia, L., Vancurova, L., Škaloud, P., Peksa, O., Wedin, M., and Grube, M. (2013). The symbiotic playground of lichen thalli - a highly flexible photobiont association in rock-inhabiting lichens. FEMS Microbiol. Ecol. 85, 313-323. doi: 10.1111/1574-6941.12120

Nei, M. (1987). Molecular Evolutionary Genetics. New York: Columbia Univ. Press.

Nelsen, M. P., and Gargas, A. (2009). Symbiont flexibility in Thamnolia vermicularis (Pertusariales: Icmadophilaceae). Bryologist 112, 404-417. doi: 10.1639/0007-2745-112.2.404

Nosil, P., and Mooers, A. Ø. (2005). Testing hypotheses about ecological specialization using phylogenetic trees. Evolution 59, 2256-2263. doi: 10.1111/ j.0014-3820.2005.tb00933.x

Oksanen, J., Blanchet, F. G., Kindt, R., Legendre, P., Minchin, P., O’Hara, R., et al. (2012). Vegan: Community Ecology Package. R package version 2.0-2.

Ortiz-Álvarez, R., de los Ríos, A., Fernández-Mendoza, F., Torralba-Burrial, A., and Pérez-Ortega, S. (2015). Ecological specialization of two photobiontspecific maritime cyanolichen species of the genus Lichina. PLoS One 10:e0132718. doi: 10.1371/journal.pone.0132718

Pagel, M. (1999). Inferring the historical patterns of biological evolution. Nature 401, 877-884. doi: 10.1038/44766

Parkinson, J. E., and Baums, I. B. (2014). The extended phenotypes of marine symbioses: ecological and evolutionary consequences of intraspecific genetic diversity in coral-algal associations. Front. Microbiol. 5. doi: 10.3389/ fmicb.2014.00445

Paul, F., Otte, J., Schmitt, I., and Dal Grande, F. (2018). Comparing sanger sequencing and high-throughput metabarcoding for inferring photobiont diversity in lichens. Sci. Rep. 8, 8624. doi: 10.1038/s41598-018-26947-8

Peksa, O., and Škaloud, P. (2011). Do photobionts influence the ecology of lichens? A case study of environmental preferences in symbiotic green alga Asterochloris (Trebouxiophyceae). Mol. Ecol. 20, 3936-3948. doi: 10.1111/j.1365-294X.2011.05168.x

Pérez-Ortega, S., Ortiz-Álvarez, R., Allan Green, T. G., and de los Ríos, A., (2012). Lichen myco- and photobiont diversity and their relationships at the edge of life (McMurdo Dry Valleys, Antarctica). FEMS Microbiol. Ecol. 82, 429-448. doi: 10.1111/j.1574-6941.2012.01422.x

Piercey-Normore, M. D. (2006). The lichen-forming ascomycete Evernia mesomorpha associates with multiple genotypes of Trebouxia jamesii. New Phytol. 169, 331-344. doi: 10.1111/j.1469-8137.2005.01576.x

Pino-Bodas, R., and Stenroos, S. (2021). Global biodiversity patterns of the photobionts associated with the genus Cladonia (Lecanorales, Ascomycota). Microb. Ecol. 82, 173-187. doi: 10.1007/s00248-020-01633-3

Poland, D. M., Mansfield, J. M., Hannes, A. R., Lewis, C. L. F., Shearer, T. L., Connelly, S. J., et al. (2013). Variation in Symbiodinium communities in juvenile Briareum asbestinum (Cnidaria: Octocorallia) over temporal and spatial scales. Mar. Ecol. Prog. Ser. 476, 23-37. doi: 10.3354/meps 10165

R Core Team (2020). R: A Language and Environment for Statistical Computing. $\mathrm{R}$ Foundation for Statistical Computing. Vienna, Austria.

Revell, L. J. (2012). Phytools: an R package for phylogenetic comparative biology (and other things). Methods Ecol. Evol. 3, 217-223. doi: 10.1111/j.2041-210X.2011.00169.x

Rintelen, T., von Wilson, A. B., Meyer, A., and Glaubrecht, M. (2004). Escalation and trophic specialization drive adaptive radiation of freshwater gastropods in ancient lakes on Sulawesi, Indonesia. Proc. R. Soc. Lond. Ser. B Biol. Sci. 271, 2541-2549. doi: 10.1098/rspb.2004.2842

Rolshausen, G., Grande, F. D., Sadowska-Deś, A. D., Otte, J., and Schmitt, I. (2018). Quantifying the climatic niche of symbiont partners in a lichen symbiosis indicates mutualist-mediated niche expansions. Ecography 41, 1380-1392. doi: 10.1111/ecog.03457

Rolshausen, G., Hallman, U., Grande, F. D., Otte, J., Knudsen, K., and Schmitt, I. (2020). Expanding the mutualistic niche: parallel symbiont turnover along climatic gradients. Proc. R. Soc. B Biol. Sci. 287:20192311. doi: 10.1098/ rspb.2019.2311

Rowan, R. (2004). Thermal adaptation in reef coral symbionts. Nature 430:742. doi: $10.1038 / 430742 \mathrm{a}$

Rundell, R. J., and Price, T. D. (2009). Adaptive radiation, nonadaptive radiation, ecological speciation and nonecological speciation. Trends Ecol. Evol. 24, 394-399. doi: 10.1016/j.tree.2009.02.007

Sadowsky, A., Mettler-Altmann, T., and Ott, S. (2016). Metabolic response to desiccation stress in strains of green algal photobionts (Trebouxia) from two Antarctic lichens of southern habitats. Phycologia 55, 703-714. doi: $10.2216 / 15-127.1$

Sánchez-Benítez, A., García-Herrera, R., and Vicente-Serrano, S. M. (2017). Revisiting precipitation variability, trends and drivers in the Canary Islands. Int. J. Climatol. 37, 3565-3576. doi: 10.1002/joc.4937

Sanders, W. B., and Masumoto, H. (2021). Lichen algae: the photosynthetic partners in lichen symbioses. Lichenologist 53, 347-393. doi: 10.1017/ S0024282921000335

Schluter, D. (2000). The Ecology of Adaptive Radiation. OUP Oxford.

Shankar, V., Agans, R., and Paliy, O. (2017). Advantages of phylogenetic distance based constrained ordination analyses for the examination of microbial communities. Sci. Rep. 7, 6481. doi: 10.1038/s41598-017-06693-z

Singh, G., Dal Grande, F., Divakar, P. K., Otte, J., Crespo, A., and Schmitt, I. (2017). Fungal-algal association patterns in lichen symbiosis linked to macroclimate. New Phytol. 214, 317-329. doi: 10.1111/nph.14366

Sparrius, L. B., Aptroot, A., Sipman, H. J. M., Pérez-Vargas, I., Matos, P., Gerlach, A., et al. (2017). Estimating the population size of the endemic lichens Anzia centrifuga (Parmeliaceae) and Ramalina species (Ramalinaceae) on Porto Santo (Madeira archipelago). Bryologist 120, 293-301. doi: 10.1639/0007-2745-120.3.293

Spjut, R., Simon, A., Guissard, M., Magain, N., and Sérusiaux, E. (2020). The fruticose genera in the Ramalinaceae (Ascomycota, Lecanoromycetes): their 
diversity and evolutionary history. MycoKeys 73, 1-68. doi: 10.3897/ mycokeys.73.47287

Stamatakis, A. (2014). RAxML version 8: a tool for phylogenetic analysis and post-analysis of large phylogenies. Bioinformatics 30, 1312-1313. doi: 10.1093/ bioinformatics/btu033

Stevens, G. N. (1987). The lichen genus Ramalina in Australia. Bull. Br. Mus. Nat. 16, 107-223.

Templeton, A. R., Crandall, K. A., and Sing, C. F. (1992). A cladistic analysis of phenotypic associations with haplotypes inferred from restriction endonuclease mapping and DNA sequence data. III. Cladogram estimation. Genetics 132, 619-633. doi: 10.1093/genetics/132.2.619

Vančurová, L., Muggia, L., Peksa, O., Řídká, T., and Škaloud, P. (2018). The complexity of symbiotic interactions influences the ecological amplitude of the host: A case study in Stereocaulon (lichenized Ascomycota). Mol. Ecol. 27, 3016-3033. doi: 10.1111/mec.14764

Vančurová, L., Peksa, O., Němcová, Y., and Škaloud, P. (2015). Vulcanochloris (Trebouxiales, Trebouxiophyceae), a new genus of lichen photobiont from La Palma, Canary Islands, Spain. Phytotaxa 219:118. doi: 10.11646/ phytotaxa.219.2.2

Vázquez, D. P., Melián, C. J., Williams, N. M., Blüthgen, N., Krasnov, B. R., and Poulin, R. (2007). Species abundance and asymmetric interaction strength in ecological networks. Oikos 116, 1120-1127. doi: 10.1111/j.0030-1299.2007.15828.x

Warren, B. H., Simberloff, D., Ricklefs, R. E., Aguilée, R., Condamine, F. L., Gravel, D., et al. (2015). Islands as model systems in ecology and evolution: prospects fifty years after MacArthur-Wilson. Ecol. Lett. 18, 200-217. doi: 10.1111/ele. 12398

Weiss, S., Xu, Z. Z., Peddada, S., Amir, A., Bittinger, K., Gonzalez, A., et al. (2017). Normalization and microbial differential abundance strategies depend upon data characteristics. Microbiome 5, 1-18. doi: 10.1186/s40168-017-0237-y
Whittaker, R. J., and Fernández-Palacios, J. M. (2007). Island Biogeography: Ecology, Evolution, and Conservation. Oxford University Press, Oxford.

Xu, M., De Boer, H., Olafsdottir, E. S., Omarsdottir, S., and Heidmarsson, S. (2020). Phylogenetic diversity of the lichenized algal genus Trebouxia (Trebouxiophyceae, Chlorophyta): a new lineage and novel insights from fungal-algal association patterns of Icelandic cetrarioid lichens (Parmeliaceae, Ascomycota). Bot. J. Linn. Soc. 194, 460-468. doi: 10.1093/botlinnean/ boaa 050

Yamashita, H., Suzuki, G., Hayashibara, T., and Koike, K. (2013). Acropora recruits harbor "rare" Symbiodinium in the environmental pool. Coral Reefs 32, 355-366. doi: 10.1007/s00338-012-0980-2

Conflict of Interest: The authors declare that the research was conducted in the absence of any commercial or financial relationships that could be construed as a potential conflict of interest.

Publisher's Note: All claims expressed in this article are solely those of the authors and do not necessarily represent those of their affiliated organizations, or those of the publisher, the editors and the reviewers. Any product that may be evaluated in this article, or claim that may be made by its manufacturer, is not guaranteed or endorsed by the publisher.

Copyright (c) 2022 Blázquez, Hernández-Moreno, Gasulla, Pérez-Vargas and PérezOrtega. This is an open-access article distributed under the terms of the Creative Commons Attribution License (CC BY). The use, distribution or reproduction in other forums is permitted, provided the original author(s) and the copyright owner(s) are credited and that the original publication in this journal is cited, in accordance with accepted academic practice. No use, distribution or reproduction is permitted which does not comply with these terms. 